\title{
Informing Systems as the Transformers of Information Wave into Virtual Civilization and Their Ethics Question
}

\author{
Andrew Targowski \\ Western Michigan University, Kalamazoo, Michigan, USA
}

\section{andrew.targowski@wmich.edu}

\begin{abstract}
The purpose of this investigation is to define the central contents and issues of the impact of informing systems on the rise and development of the Virtual Civilization. The methodology is based on an interdisciplinary big-picture view of the Virtual Civilization's elements of development and their interdependency. Among the findings are the following: Virtual Civilization has infrastructural characteristics, a world-wide unlimited, socially constructed work and leisure space in cyberspace, and it can last centuries/millennia - as long as informing systems are operational. Practical implications: The mission of Virtual Civilization is to control the public policy of real civilizations in order to secure the common good in real societies. Social implication: The quest for the common good by virtual society may limit or even replace representative democracy by direct democracy which, while positively solving some problems, may eventually trigger permanent political chaos in real civilizations. Originality: This investigation, by providing an interdisciplinary and civilizational approach at the big-picture level, defined the ethics question of the role of informing systems in the development of Virtual Civilization.
\end{abstract}

Keywords: Informing systems, Informing science, Information Wave, Virtual Wave, Civilization, Global Civilization, Virtual Civilization, Virtuality, Cyberspace, Cognitive space, e-Nation.

\section{Introduction}

This paper applies the civilizational approach to the understanding of the role of information and communication in the development of civilization at the levels of society, culture, and infrastructure. This approach treats a civilization as a live organism, larger than a nation, region, city, and village.

This investigation particularly aims at the impact of information and communication in civilizations that are active in the $21^{\text {st }}$ century. The purpose of this enquiry is to evaluate the impact of

Material published as part of this publication, either on-line or in print, is copyrighted by the Informing Science Institute. Permission to make digital or paper copy of part or all of these works for personal or classroom use is granted without fee provided that the copies are not made or distributed for profit or commercial advantage AND that copies 1) bear this notice in full and 2) give the full citation on the first page. It is permissible to abstract these works so long as credit is given. To copy in all other cases or to republish or to post on a server or to redistribute to lists requires specific permission and payment of a fee. Contact Publisher@InformingScience.org to request redistribution permission. informing systems on the development of the contemporary civilization, which begun about 6,000 years ago in 4,000 BC. This development is leading to the uprising of a Virtual Civilization in the $21^{\text {st }}$ century. Also, this inquiry emphasizes the role of informing science in the development of a Virtual Civilization. By civilization, one can assume the following meaning (Targowski, 2009b): 
A civilization is a complex of compatibly interactive entities of society, culture(s) and infrastructure in a large frame of territory and time, usually embracing several nations and centuries/millennia.

So far the development and operations of social systems are investigated at rather small levels, such as family, village, city, and specific culture, nation, and region. Since the fall of the Berlin Wall in 1991, we face the clash of civilizations (Huntington, 1996) as the New World Order in the $21^{\text {st }}$ century. For example, it is not enough to say that the clash is only between the United States and ISIS. The clash is between Western and Islamic Civilizations today.

Analyzing the social change at the civilization level reflects the social change over large distances and long times. For example, the Western Civilization is functioning in America, Europe, Australia, and New Zealand for about the last 1200 years. Similarly, the Islam Civilization is functioning in the Middle East, Africa, and Indonesia for about the last 1385 years. In the $21^{\text {st }}$ century the major civilizations can be broken down to separate categories: Western, Eastern, Chinese, Japanese, Islam, Buddhist, Hindu, and African. These civilizations are dispersing through the whole globe through the means of individuals who immigrate to study, work, and live, yet who are in good real-time communication among their families and friends in different countries today.

How it is possible? Paper-based civilization cannot secure such good communication, even oral, telephone-based communication just slightly improved trans-civilizational communication in the $20^{\text {th }}$ century. But the development of informing systems has transformed back office-oriented information-communication technology into real-time control systems into front office and interpersonal powerful info-communication that is embraced by almost every organization in the world and several billion people. This process is so powerful and overwhelming that it transforms real civilization into a virtual civilization that has tremendous impact on the social modus operendi of the society. The first foundation of informing science was laid down by Eli Cohen (1999, p. 5 ) as "the field of inquiry that attempts to provide a client with information in form, format, and schedule that maximizes its effectiveness." According to Zbigniew Gackowski (2011, p. 35), "If information denotes anything in form, the term informing can be defined as nothing more than developing and spreading patterns, that are represented by physical states." This author considers that information conveys meaningful content, expressed as a noun, and informing means communication process, expressed as a verb.

One can notice that terms such as information technology (IT) or informatics do not reflect the progress which took place in the world-wide communication ability when the Internet became a utility and wireless mobile communication became nowadays the unprecedented factor in making the world "flat" and full of parallel online communities. In Europe, this new online world environment triggered by digital technology is called information and communication technology (ICT) which still, historically speaking, implies mostly the application of private networking, the Internet, and mobile channels, rather than dynamic online modus operandi of about a few billion people using smart phones in every corner of the world, mostly communicating through social media and texting faceless agents. Hence, informing is a better term since the term ICT emphasizes the process of "printed and displayed reports". It is a matter of fact that the term computer science passed the similar reconfiguration when it was called as computing, inspired by Denning et al. (1989, pp.2-23).

By informing systems [supported by informing science (Cohen, 1999)] one can understand the following:

Informing systems provide their users with info-communication meaningful content and channels in cognitive, real and virtual spaces in a form, format, and schedule that opti- 
mizes its efficiency, eventually effectiveness (some efficient systems are not necessarily effective) and preferably sustainability.

As the term has evolved over the years within informing science, an informing system may or may not involve information or communications technology. For the purposes of the present paper, however, when the term is used it will specifically refer to systems in which technologies play a role--which is consistent with the term's early usage.

Informing systems viewed as a component of the infrastructure of civilization are unlimited combinations of information systems and communication systems which create the global cyberspace and INFOCO systems (Targowski, 2009a, p. 84); in fact, their synonym is informing systems. This is an entity built on electromagnetic waves, imposing feelings that "distance is dead?" (Cairncross, 1997). Frances Cairncross (1997) argues that the story today is not only the diminishing importance of distance, but also the mobility and ubiquity of technology. Its impact caused, for example, the rise and fall of the dot-com phenomenon at the beginning of the $21^{\text {st }}$ century, the global spread of mobile telephones and other wireless communications, the wave of technology mergers, the authenticity of the 'new economy', diverging trends in business-toconsumer and business-to-business e-commerce, the restructuring of the organization in the wake of the Internet, the increasing impact of patent law on the communications economy, the so-called 'digital divide', and the democratizing effects of communications technology on companies, governments, and society. A typology of informing systems is depicted in Figure 1. This typology is a continuation of the effort provided by Eli Cohen who was the first who provided a typology of informing systems (Cohen, 1999).

Certainly informing systems transform Homo libris (1452-2000) with mental 3D into Homo electronicus (2000-) with mental 4D (3D plus cyberspace) and space and time free in cognitive, real and virtual (cyberspace-driven) environment (Targowski, 2009a, p. 84). A very new environment as virtual/cyberspace has been developing in the $21^{\text {st }}$ century which has tremendous impact on the civilization development today.

Informing systems and informing science (Cohen, 1999) to certain degree also transform the study of civilization from a passive history-oriented investigation that, for example, had happen 6000 years ago, into the dynamic investigations of the contemporary civilization as the civilizational entities (society, culture, or infrastructure) impact each other not through centuries and millennia but in real-time as we short time living humans can see, feel, and react upon in the $21^{\text {st }}$ century.

\section{The Development of Civilization}

The scientific and comprehensive investigation of civilization was accomplished by English historian Arnold Toynbee (1889-1975) published his greatest work in the twelve-volume $A$ Study of History [(1934-61) (Toynbee, 1995)], where he compared the history of twenty six different civilizations and argued that each follows a similar pattern of evolution through a cyclical pattern of growth, maturity, and decay. He believed that societies thrive best in response to challenges and that a society's most important task is to create a religion. He stressed religious and philosophical factors as guiding civilizations.

There is only one world civilization, yet there are about 26 main autonomous civilizations that have developed in the last 6,000 years. Perhaps, if one included satellite civilizations (cultures), this number could possibly reach about 100 or even more. However, for the clarity of this synthesis we would like to limit the scope to the foremost 26 autonomous civilizations. 


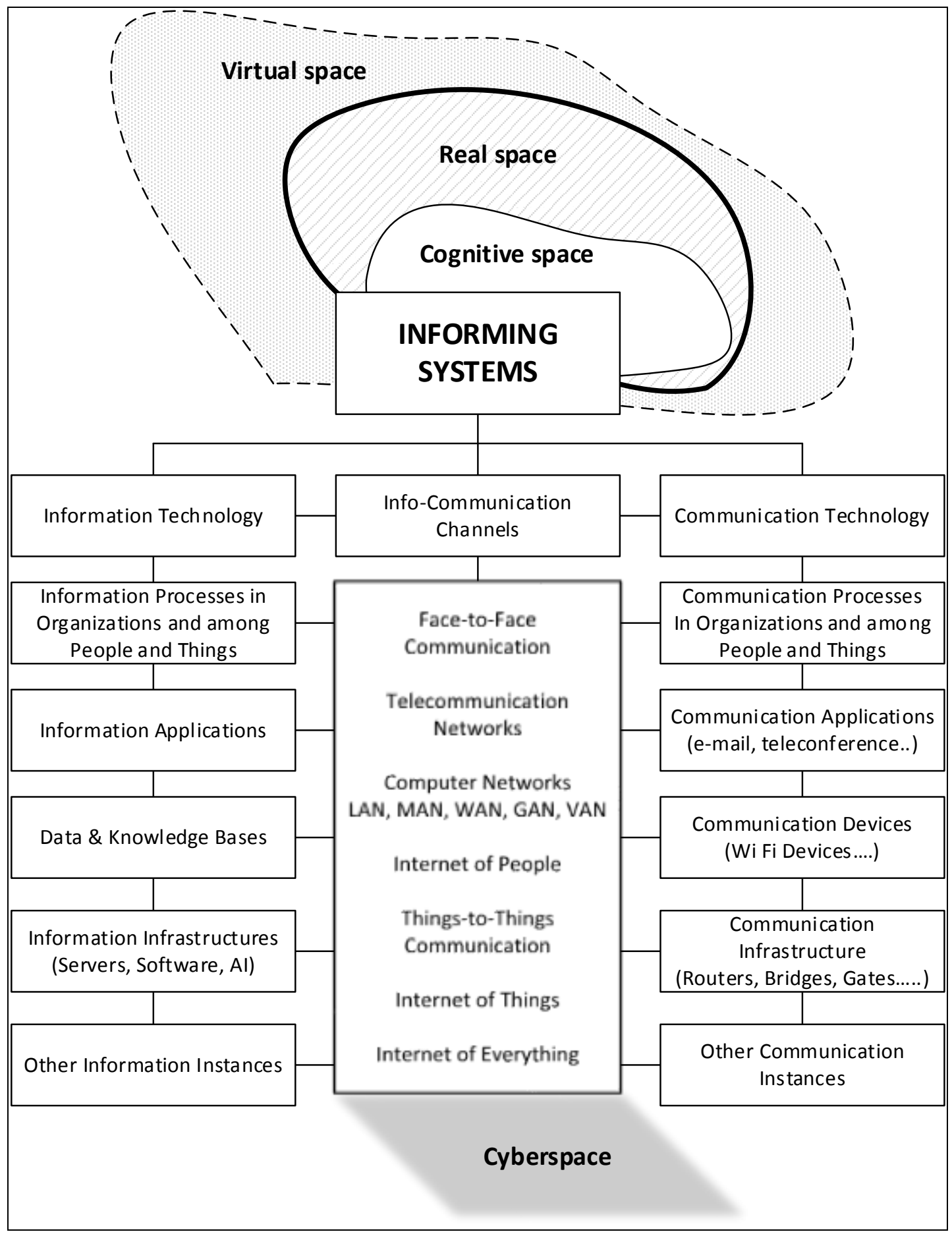

Figure 1. A Typology of Informing Systems (The Targowski Model), where Cyberspace reflects the Technological Dimension and Virtual Space Depicts the Societal Dimension as Seen in the $21^{\text {st }}$ Century.

The world civilization as a continuum never dies - it only evolves from one stage to another. This evolution takes place through the life cycle of autonomous civilizations. At the very beginning of human civilization there were several successful formations of living processes that could be considered autonomous civilizations. They took place in different parts of the world, and there 
were about eight cases. The first autonomous civilization was the Mesopotamian Civilization (including Sumerian), which emerged in the valley of the Euphrates-Tigris rivers in the Middle East at about 4,000 B.C. In the Far-East, the first autonomous civilizations rose inland: Indus (Harrappan) about 2,500 B.C. and Sinic about 1,500. In Africa the initial civilization was the Berberic-Carthagean Civilization 600 B.C., and in South America early autonomous civilizations included the Andean Civilization that emerged about 1500 B.C.. In Central America the first autonomous civilization was the Meso-American Civilization which rose $1000 \mathrm{BC}$. Both civilizations fell about $1600 \mathrm{AD}$.

Autonomous civilizations rose in response to physical challenges of nature (ecosystem). Humans began to organize themselves into a society, which provided exchangeable and specialized services, such as food hunting, food production, house building, road construction, transportation, health care, entertainment, and so forth. These services and growing human communication led towards the formation of cities. These types of autonomous civilizations we will call societal civilizations.

In addition to the environmental challenges, the societal civilization as a whole has been threatened by its own internal structure involving power, wealth creation, beliefs enforcement, family formation, leadership, and so forth. As societal civilizations evolved into more complex entities, they were managed by cultural manipulation. These types of autonomous civilizations we will refer to as cultural civilizations. By culture, we understand a value-driven patterned behavior of a human entity.

Ever since religion was transformed from beliefs in magic to beliefs in poly-gods and then to a mono-god, cultural civilization has applied religion as the main tool of cultural control. Religious and military forces were the foundations of the power apparatus that maintained the society as a governed entity. These forces civilized society and moved it into higher levels of organization. Among cultural civilizations one can recognize about 16 cases, such as the Egyptian Civilization 3100 B.C., the Minoan 2700 B.C., the Mycean Civilization 1500 B.C., the Sinic Civilization 1500 B.C., the Hellenic Civilization 750 B.C., the Canaanite Civilization 1100 B.C., the Hindu Civilization 600 B.C., the Roman Civilization 31 B.C., the Eastern Civilization 350 A.D., the Hellenistic Civilization 323 B.C., the Buddhist Civilization 600 A.D., the Ethiopian Civilization 400 A.D., the Sub-Saharan Civilization 800 A.D., the Western Civilization 800 A.D., the Islamic Civilization 1300 A.D., and the Maghrebian Civilization 1000 A.D. Cultural civilization evolves into a civilization with challenges generated by intra- and inter-civilizational issues of war and peace. These types of issues have been managed by technological means of domination. Such civilizations we will call infrastructural civilizations (Targowski, 2009a).

Infrastructural civilization's purpose is to expand spheres of influence with the means of technology. Technology drives the development of infrastructural civilizations. The prime target of technological applications has been the military which supports the main values of a given civilization. By-products of militaristic applications of technology affect the civilian part of its infrastructure. Among eight infrastructural civilizations one can recognize the Sinic Civilization 1500 B.C., the Hindu Civilization 600 B.C., the Japanese Civilization 650 A.D., the Western Civilization 800 A.D., the Eastern Civilization 350 A.D., the Buddhist Civilization 600 A.D., the Islamic Civilization 1300 A.D., and the African Civilization 1847 A.D (after the Berlin Treaty).

By the end of the 2nd Millennium, infrastructural civilizations had become civilizations responsible for world hemisphere influence and domination. Hence, Western Civilization dominates the Western Hemisphere, Eastern and Hindu rule the Eastern Hemisphere, the Islamic Civilization rules the Near and Middle East Hemisphere and some parts of the Far East Hemisphere, the Japanese Civilization governs some parts of the Far East Hemisphere, the Chinese Civilization influ- 
ences the majority of the Far East Hemisphere, and the Buddhist civilization influences a small part of the Far East Hemisphere.

The process of evolving civilizations at the end of the $20^{\text {th }}$ century is depicted in Figure 2 according to the kinds of challenges they face and their responses.

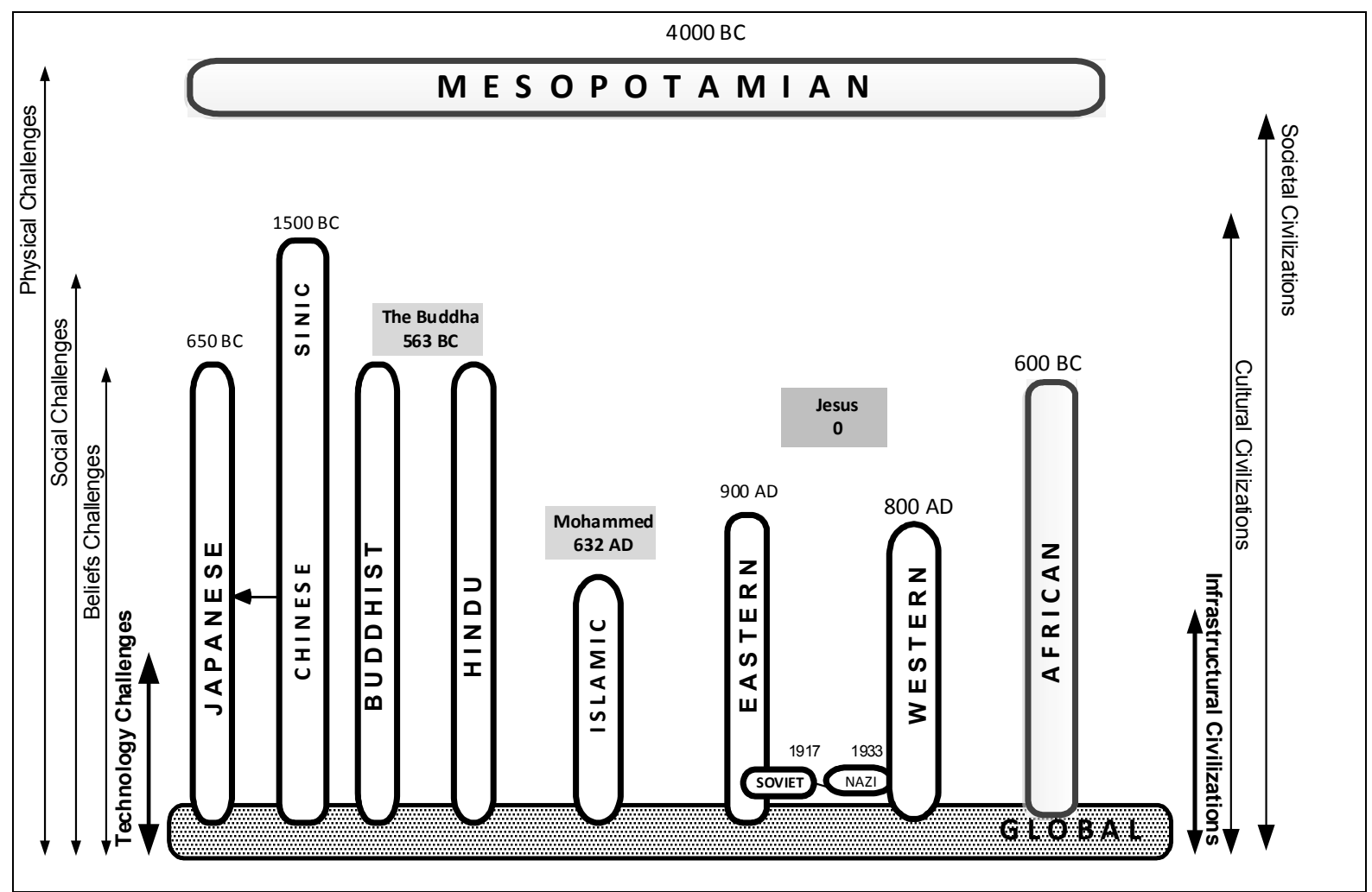

Figure 2. The Process of Evolving Civilizations at the End of the $20^{\text {th }}$ Century.

According to a composite definition of a civilization (Targowski, 2009b), it is characterized by the following important attributes:

1) Large society

a. Specializing in labor

b. Self-differentiating

c. Sharing the same knowledge system

2) Space and Time

a. Autonomous fuzzy reification

b. Distinguished and extended area or period of time

c. Reification not a part of a larger entity

3) Cultural system, values and symbol-driven

a. Communication driven (e.g.: literate and electronic media)

b. Religion, wealth and power driven

4) Infrastructural system, technology-driven by first at least one of the following:

a. Urban infrastructure

b. Agricultural infrastructure

c. Informing systems infrastructure

d. Other infrastructures (industrial, information and so forth)

5) Cycle-driven, rising, growing, declining, and falling over time

6) Spaces; cognitive, real, and virtual 
Based on these attributes, the composite (a short definition of civilization was provided earlier in this text) definition of civilization is as follows (Targowski, 2009b):

Civilization is a large society living in an autonomous, fuzzy reification (invisible-visible) which is not a part of larger one and exists over an extended period of time. It specializes in labor and differentiates from other civilizations by developing its own advanced cultural system driven by communication, religion, wealth, power, and sharing the same knowledge/wisdom system within complex urban, agricultural infrastructures, and others such as industrial and information ones. It also progresses in a cycle or cycles of rising, growing, declining and falling in cognitive, real, and virtual spaces.

A graphic model of civilization is illustrated in Figure 3.

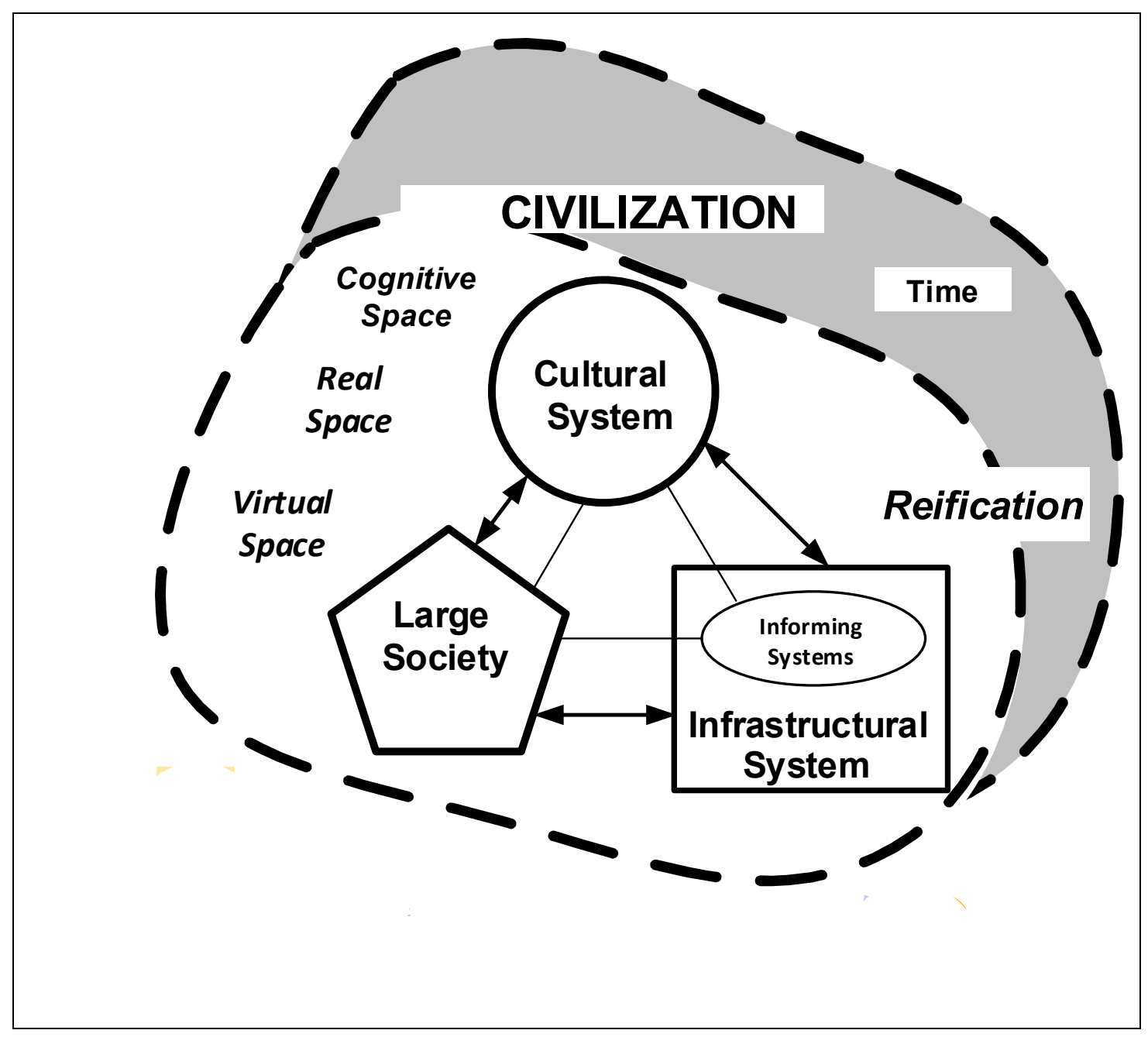

Figure 3. A Model of Civilization with Informing Systems and their place in the Dynamics of Civilization

Civilizations are dynamic and rise, grow, decline, and disappear or transform into other ones. Usually the developmental process of civilization can be divided in states (feudal systems, state systems, and imperial systems) (Melko 1969). However, in the study of the history of political or technological developments, the time categories are usually considered as "ages," "eras," and "waves." 
Informing Systems and Information Waves

By an "age" one can understand a dominant technology or political system applied in practice at a certain time, although a given technology/political system is sooner or later replaced by the next "age" of progressive or regressive solutions. An "era" is a synonym for "age" but implies a long "age." Also an "era" can be replaced by the next "era" of a progressive or regressive solution.

A "wave" is associated with the production, processing, or trade of a kind of food, good, or information related to a new technology or new rules. It has a very strong impact upon the modus operandi of a society. It is not replaceable, but is impacted by the next wave of technology.

\section{Ages, Eras, and Waves of Civilization with Special Consideration to the Role of Information Handling}

Man has survived longer than stronger animals because he has had an important advantage: a brain driven by information-communication. With a brain, mankind has been able to learn, communicate, and develop a structure of consciousness. At first, the nose was the most important organ for the archaic, nomadic hunters. Then, about 200,000 years ago, the human information system began "upgrading" human consciousness through emotions and rituals, and the ear became the most important organ for those hunters. Their ears developed an appreciation for music and dance. That was the first advanced pattern of human cultural behavior. About 10,000 years ago, consciousness became mythical and 2-dimensional, with some appreciation for the natural tempo of events.

Mankind started farming, dreaming of a better social order for its members, and creating myths through symbolic imagination and language-driven communication. At this time, then, the mouth became the most important organ. Around $5000 \mathrm{BC}$, the Egyptian calendar, regulated by the Sun and Moon in 360 days (12 months of 30 days each), became the first organized information system (IS) device that supported man's survival and development. About 1000 years later, the Sumerians developed writing and organizational patterns for "civilized" cities. About 2,500 BC, the structure of consciousness became mental and 3-dimensional, with a sense of abstract time, cultural curiosity for science and art, dogma, rules, and laws. The first knowledge centers appeared in Egypt, where written literature lamented about the meaning of life using papyrus and collecting them in the first World's Library in Alexandria. The manufacturing of objects and the production of food (bread, beer) took place. Thus, the eye became the most important organ for the awakened man with volition and reflection about himself and the world (Simpson, 1991).

For extended periods of time, the evolution of the Earth was understood as being regulated by a relationship between nature's internal forces such as gravity, atomic dynamics, time, and space dynamics. Today, the problem of life on Earth has become a puzzle based upon relationships (info-communication) among people and their level of cognition, and communicating this through information-knowledge systems.

The tool in achieving this role is knowledge, disseminated first by books and now by computers and their networks. Mediated communication has a long story. The invention of the printing press by Johann Gutenberg in 1454 boosted the spread of knowledge. This has become the most significant invention to separate written print from the spoken world. Printing soon became a means of disseminating and intensifying intellectual endeavors. Before Gutenberg, each volume was handwritten, often by monks. In the $15^{\text {th }}$ century, a book was as costly and as rare as jewels.

Before the printing press, scientists would take long trips merely to familiarize themselves with the content of a certain book. The enlightened ruler Carl IV of Luxembourg collected 114 volumes, while the French king Carl V, amassed as many as 900. Then, printing houses began to print hundreds of books (2-3). By the year 1500, within 50 years of the invention of the German press (One must mention that woodblock printing of written characters was known in China by 
A.D. 350. Ceramic movable type was in use in China about A.D. 1040. The Koreans invented print in the $5^{\text {th }}$ century; however, it was not applied widely and became unknown for others outside of Korea.) 30,000 reasonably priced books were in circulation (Figure 4). The satire of Erasmus of Rotterdam appeared during his lifetime in 27 editions. Print was steering thoughts and ideas in millions of people, inspiring them to speed, simplify, and strengthen the work of the mind.

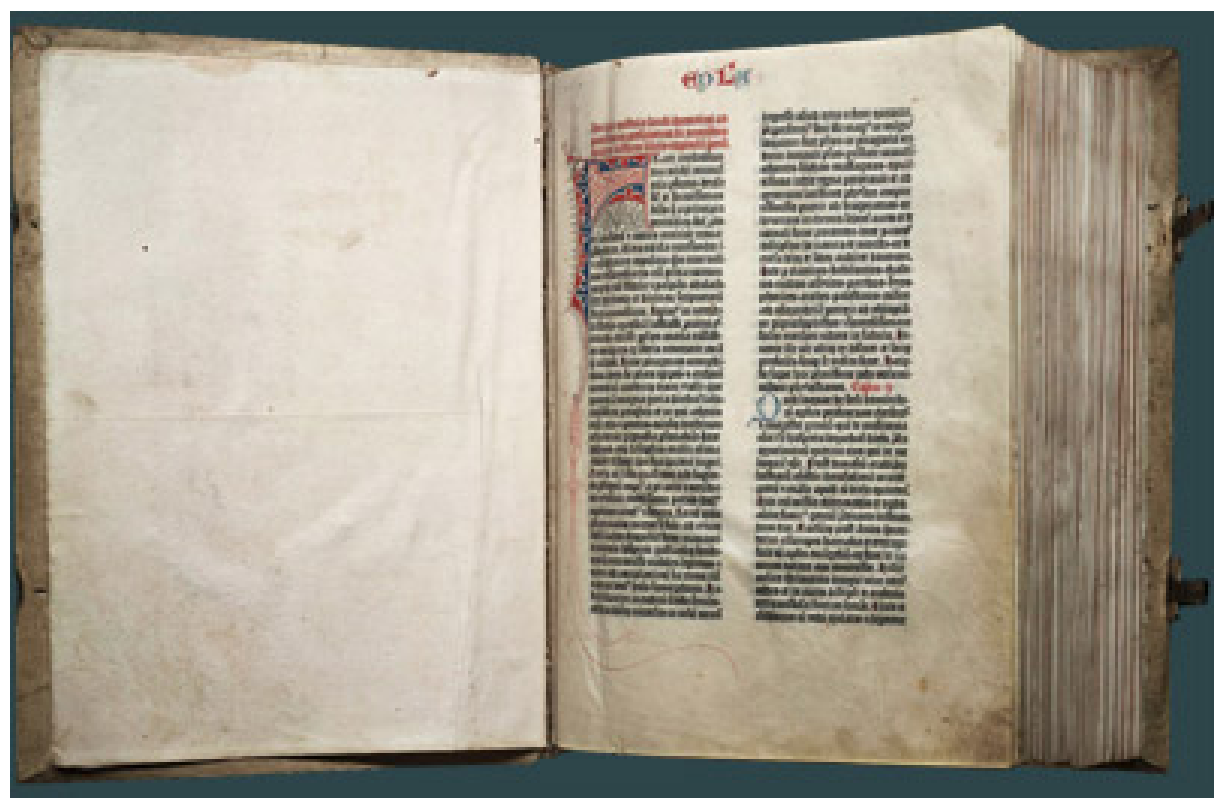

Figure 4. The Gutenberg Press modernized civilization for the next 500+ years. (Photo: Library of Congress, www.loc.gov)

The printed alphabet in book form, which was the first "computer terminal," became an absorber and transformer of civilization. New media such as letters and printed books altered the relationship between our senses and changed the mental (information processing) process. Print made a split between the head and heart which has become a trauma, affecting Western Civilization up to the present (McLuhan, 1962). It created government regulations, but it also inspired individualism and opposition to ideology, science, and art. Science and technology began to develop at an accelerated pace. Airplanes, cars, telegraphs, telephones, typewriters, phonographs, movies, radios, televisions, weapons, computers, automation, and telecommunications modernized human life and its story. Human consciousness has become integral and 4-dimentional (free from space and time), allowing us to enjoy learning, loving, wholeness, and wisdom for the community and ourselves. The nervous system has now become the most crucial organ, developing a "metasense." We are better at understanding rather than explaining the purpose and rules of our existence through education and research.

American physicist John Wheeler (1990) has formulated the Theory of the Participatory Universe. In this theory, observers are central to the nature of physical reality and matter is ultimately relegated to the mind. Wheeler sees the Universe as a gigantic "information processing" system with a yet-undermined output, and he has coined the phrase "IT from BIT," meaning every "thing" - a particle, a field of force, or even space-time itself - all is ultimately manifested to us through "bits" of information.

The strong role of mediated informing systems in the development of civilization began in the Control Revolution ( $19^{\text {th }}$ century) which invented telegraph, punched cards (the precursor technology which led to the development of computers in the $20^{\text {th }}$ century) and so forth to support the 
dynamics of the Industrial Revolution in the $19^{\text {th }}$ century. The following ages, waves, and eras have been strongly supported by the intensified development of informing systems. The latter transformed from mechanical-electrical apparatus to electronic computers and networks. Certain (only major) "ages," and "eras" and "waves" (not exclusive) which influence the role of information (and vice-versa) will be characterized as follows:

1. The Modernity Era (1454-1814) - transition from the Middle Ages to early modernity - invention of printed books led to the development of scientific knowledge and the application of navigation instruments (information technology) by the Portuguese sailors led to the discovery of new lands as America, and so forth.

2. The Science Age (1500-1800) - the rise of theoretical sciences and modern technology (maritime) led to the inventions of mechanical arithmometer by Blaise Pascal and Gottfried W. Leibnitz, which were precursors of future information technology.

3. The Revolution Age (1685-1917) - The English, American, French, and Bolshevik Revolutions. Claude Chappe invented a coded information system, communicated through light beams from one tower to another one with operators who read and sent such mediated information to the next tower. This system was installed to protect the French Revolution. Later Napoleon expanded this system to protect his regime.

4. The Modern Era (1814-1914) - the Industrial Revolution (the engine, electricity, and the factory system) led to the complex processes which needed complex calculations. A punched tape was applied by Joseph Jacquard in steering a loom which inspired Charles Babbage to invent first mechanical "analytical engine," which was the first ever programmable "computer." The trade needed long-distance communication which led to the inventions of telegraph with Morse code and punched cards (invented by Herman Hollerith), which gave the foundation for the rise of modern information technology and its applications in business and governments.

5. The Control Revolution ( lantic cable, telephones, cash registers, adding machines, motion pictures, wireless telegraphs, and radios were supporting the rising bureaucracy (today bureaucracy is a symptom of inefficient office), which was looking for better efficiency (productivity) of offices.

6. The Modernity Era (1914-1990s) - technological innovations of the $19^{\text {th }}$ century were applied on a large scale during peace and war times. The invention of car and airplane led to the technology-intensive wars and supporting them businesses and eventually the needs for advancement in information technology. One of this kind of applications was the Social Security System, which needed efficient configurations of punched cards machines delivered by IBM and Univac in the United States. In Europe the Bull Company was making such machines. The encryption technology led to the development of binary language (Cl. Shannon) and computers (ENIAC) and advanced applications of informing systems.

7. The Electronic Age (1940s--) - computers and transistors were invented, which provided the foundation for the rise of advanced informing systems.

8. The Computer Age (1950s-1980s) - main-frames, minis, personals, and computer networks were spreading the applications of computers for organizational informing systems.

9. The Information Age (1980s--) - application systems such as management information systems (MIS) and e-commerce. Micro computers (Apple and IBM PC) triggered the quiet revolution which led to personal computing by billions of people.

10. The Telecommunication Age (1960s--) - Satellites, break-down of AT\&T. The huge number of island computers needed to online exchange of data among them and telecommunication 
technology development was aimed at this task. Also the Cuban crisis led to the invention packet switching network (Paul Baran) which should work a Day-After (atomic blast). Informing systems became online real-time organizational tools in developed nations.

11. The Communication Age (1983--) - the Internet, e-mail, mobile communication and smartphones all as informing systems. Once the ARPANET was divided into MILINET and INTERNET (1983) and the latter became the public common network, the computer became the main online real-time ubiquitous tools of people in developed nations.

12. The Next Globalization Wave (1990s---) - world-wide-web and global economy. This trend was possible due to the Internet's easy applications around the globe. This led to the outsourcing of manufacturing to labor cheap countries and steady declined of the Western Civilization.

13. The Virtualization Age (2000s--) - virtual organizations and social networks. This trend was possible when computer storage became almost unlimited in a size and inexpensive, creating a cyberspace for unlimited virtual applications of informing systems to support organizational and personal activities.

14. The Internet of Things (2010s--) - info-communication among devises-sensor controlled. This trend is leading to machine-to-machine applications of informing systems with consequences unknown today but what can be perceived that such electronized environment will be easy for cybercrime and cyber wars.

15. Post-Modernization Era (1990s--) - from economic growth towards sustainability and from materialism towards subjective well-being as the leading ideas, but not applied on a large scale in the world societies. This trend questions the massive applications of informing systems, which not support but conquer human culture and civilization.

The curriculum of the Human Story driven by science, technology and informing systems is illustrated in Figure 5. This model tries to establish some relationships between the Political, Labor, and Intellectual Perspectives in the modern history of civilization. This period began in the Renaissance with a rebirth of learning following the darkness of the medieval period. The modern times started in 1453 when Constantinople fell to the Ottoman Turks. Many scholars who fled from the Byzantine Empire were fleeing westward for safety - (some are still fleeing). Their learning spread rapidly with the development of printing in Europe (1454). This boosted the questioning of established ideas regarding religion (Reformation), art, and science. When scholarship began to develop independently of the church, the human rather than divine in life and art was emphasized; the well rounded, informed individual (for example, Leonardo da Vinci) become the ideal.

Although civilization began about $4000 \mathrm{BCE}$, meaning it is 6000 years old, modern civilization is only about 500 years old, as it is characterized by those 15 ages, eras, and waves. To establish more synthesized periods of civilization development, one must see them in terms of waves. 


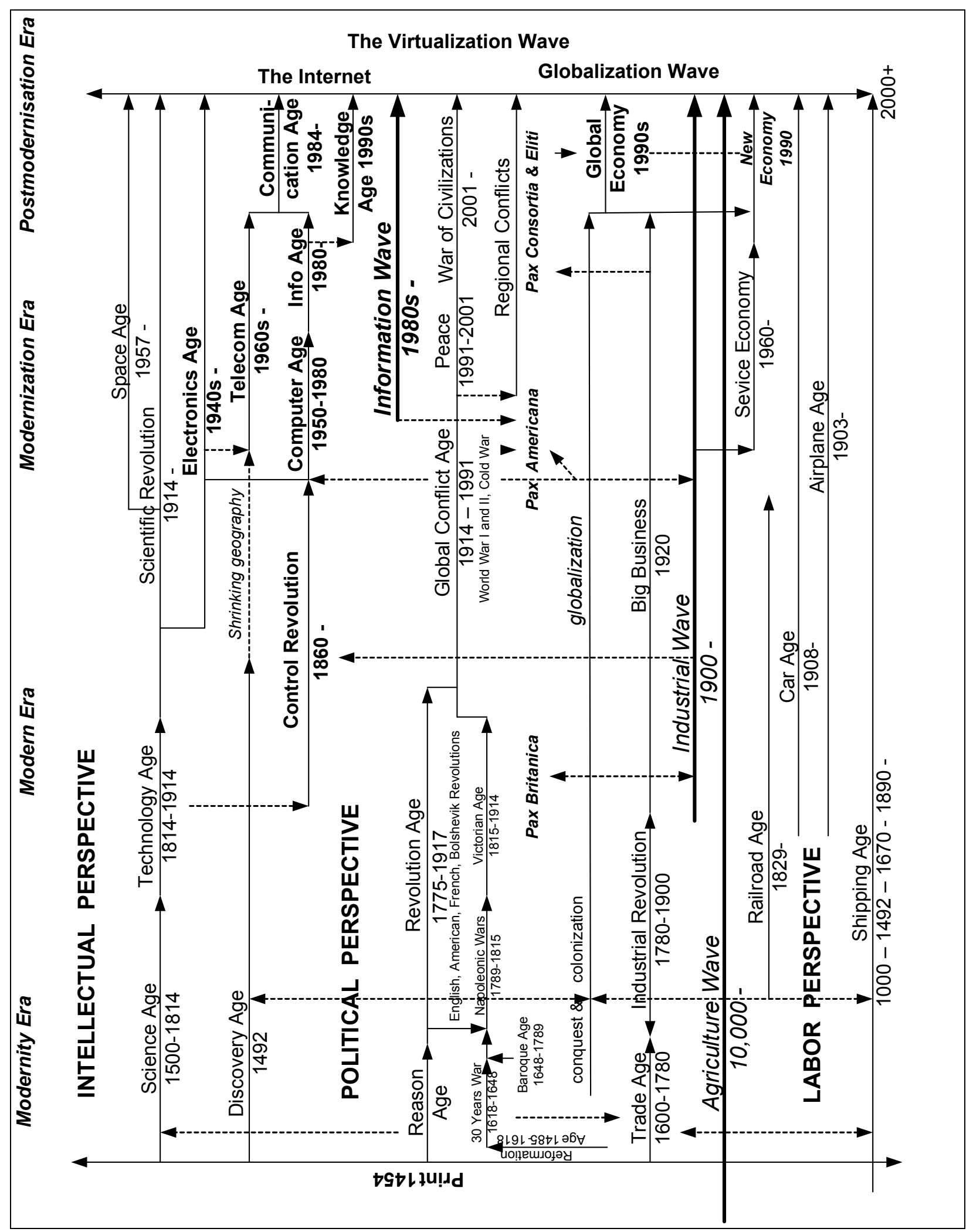

Figure 5. A Set of Civilization Ages, Eras, and Waves in the last 500+ Years (Targowski, 2009a). 
Most of the writing on waves of civilization was done by Alvin Toffler (1980) who recognized three waves: First Wave (Agriculture Wave), Second Wave (Industrial Wave), and the Third Wave (Information Wave). However, one can note additional waves in the development of humankind, which number at least seven in total nowadays (Targowski, 2009a):

0. Settlers Wave (9,000 BCE - 7,000 BCE) - from nomads to settlers.

I. Agriculture Wave (7,000 $\mathrm{BCE}+)$ - from settlers to farmers with specialized common sense knowledge and skills.

II. Industrial Wave $(1800+)$ - from farmers to workers and engineers with theoretical knowledge and skills due to education and improved handling of information.

III. Information Wave (1980+) - from material handlers to information (informing systems) handlers who improve previous waves' control and increase productivity of labor and organizations.

IV. Globalization Wave (1990+) - from local to global competition of goods and services delivery due to global informing systems making "distance dead."

V. Virtualization Waves (2000+) - steady departure from real to virtual world, mostly by young generation fluent in applying informing systems all the time - 24/7.

VI. Communicating Things Wave (2010+) - wide connectivity of machines and people to optimize all sorts of hybrid processes due to advanced smart informing systems.

The Zero Wave - the Settlers Wave -transformed hunters and farmers into settlers, who organized the first villages in the Middle East and stabilized their lives around animal domestication and food production, which after 5,000 years of wealth accumulation led to the rise of the first civilization in 4,000 BCE. It is interesting to notice that after 9,000 years $(7,000 \mathrm{BCE}-2,000)$ mankind is moving again and has become a "global hunter" for profit and jobs, while the Fourth Wave, Globalization, took off in the 1990s through the global infrastructures of infocommunication and transportation networks.

The First Wave - the Agriculture Wave - began in 7,000 BCE and will remain active as long as food is needed, which means that it will be active as long as humankind is alive. The Second Wave - the rise of the Industrial Wave - is about 200 years old. It minimized human's physical effort through mechanization and freed up time for education, which led to the Scientific Revolution and invention of aircrafts and computers. The latter has led to the Third Wave, the Information Wave, and its magic tool, the Internet. The airplane and Internet have increased human global mobility, which has triggered the Fourth Wave - The Globalization Wave.

The waves of civilization are shown in Figure 6. Each wave has its own set of civilization tools, which primarily support control processes by elites over their clients. The main control solutions for each wave are shown in this figure. It is important to notice that none of these waves replace the wave that precedes it. For example, information cannot replace food, steel, or plastic; it can only improve their creation and utilization.

Each civilization wave is not disappearing (with the exception to a certain degree of the Settlers Wave, which is a de facto pre-civilization wave). Perhaps each new wave takes the place of leadership in civilization development and selects the best talent to work for it. Furthermore, each wave perpetuates other waves, as is shown in Figure 6. Current job trends, which focus on outsourcing computing to India, contradict earlier assessments that the millennial American workforce would be heavily focused in computing. In the twenty-first century it is even possible to outsource computer programming to India, thousands miles away from Western headquarters, similarly to how manufactured goods are outsourced to China. 


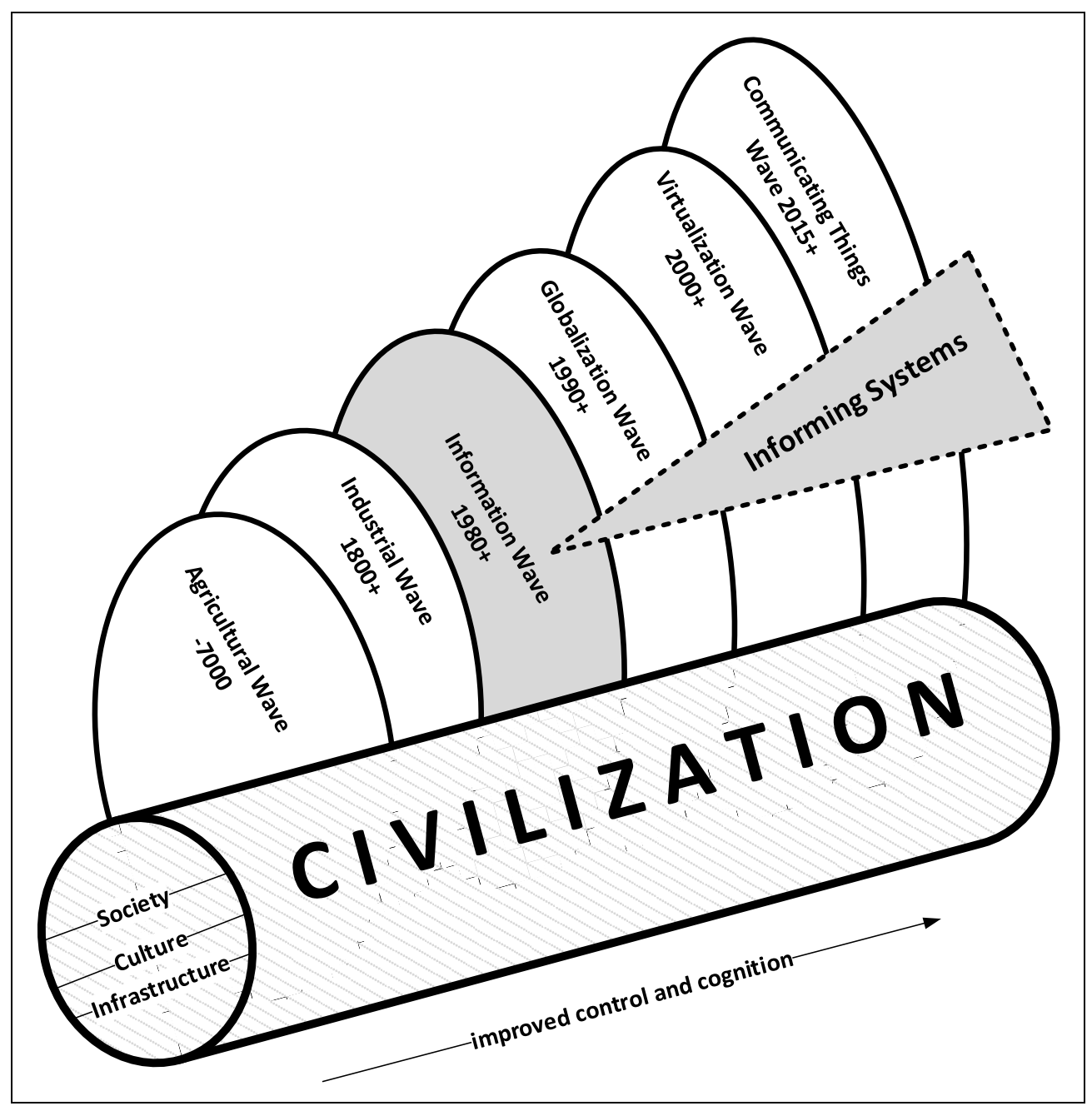

Figure 6. Civilization Waves and Emerging Informing Systems as the Transformers of Technology and Distance-based Waves

\section{The Rise of the Information Wave at the End of the $20^{\text {th }}$ Century}

As the Industrial Wave declines and the Control Revolution rises, the Information Wave rises also. The theory of post-industrialism advanced by Daniel Bell (1973) provides much of the conceptual background behind the Information Wave as the Information Society. Bell's concept of postindustrial society has five dimensions:

1. There is a shift from a goods-producing economy to a service-producing one.

2. There is an increase in size and influence of the classes of professional workers.

3. The post-industrial society is organized around theoretical knowledge.

4. A critical aim is the management of technological growth.

5. There is an emphasis on the development of methods of intellectual technology. 
Intelligent technology under the form of global computer networks dramatically expands the power of the brain into hyper-intelligence. With appropriate control programming, a network becomes a sensitive devise, not only as a physical devise, but also as an economic, social, and political one.

The spending on info-communication technology (informing systems) in the US reached $\$ 3.6$ trillion in 2012 (Hardy 2012)), which is about $22 \%$ of GDP, which is $20 \%$ more what was spent on health care that year in the U.S.!

The 19th century eliminated the wilderness through railroads. The 20th century developed science and technology that improved the well-being of many and pushed the planet to its limits resources-wise. The 21 st century perhaps will implement the Information Wave across all civilizations to improve knowledge-based, critical decisions about social life under the conditions of limited resources.

The mission of the Information Wave is (Targowski, 2009a):

To wisely control development and operations of the Agricultural Wave, Industrial Wave, Global Wave, and the other waves as well.

The goals of the Information Wave are:

1. To optimize development and operations of the Agricultural Wave, Industrial Wave, Global Wave, and the other ones in order to minimize the use of resources and ecology and to increase a citizen's choices and quality of life.

2. To sustain the development of human cognition in order to make conscious and wise decisions about the sense of human possibility, life, education, health, politics, defense, business, entertainment and leisure time.

The strategy of the Information Wave is:

To develop and apply info-communication technology in control systems (as informing systems) in a rational and human manner.

The role of the Information Wave in supporting other waves is shown in Figure 7.

These aims should be applied at all levels of civilization, including national and local governments, schools and colleges, business and other organizations, homes, and individuals. The Information Wave is composed of the following metaphoric elements through the application of informing systems (Figure 8):

- Info-factories, which generate information and seek new information; among them are the following: online enterprises, online schools and colleges, online communities, online governments, e-Republic, other.

- Info-malls, which provide the following services: e-mail, e-learning, e-banking, e-trading, e-job recruitment, e-information services, e-research, e-publishing, e-entertainment, ecalling, other.

- Infohighways, which transmit information content through info-communication services, such as: Local Area Network (LAN), Metropolitan Area Networks (MAN), Wide Area Networks (WAN), Global Area Networks (GAN), Value Area Networks (VAN), the Internet, $\mathrm{TV}$, radio broadcasting, and others.

- Cyberspace is a digital information-based dark space: that is, a dispersed, infinite constellation of digital files, databases, home pages, bulletin boards, directories, menus, and oth- 
ers, where humans with a password interactively navigate in order to create, update, exchange, and retrieve information.

- Cybernauts (netcitizens), who are informed tele-computer users with a password to access billions of information tidbits and do everything on-line from shopping and learning to working and resting. Cybernauts can be "electronic immigrants" who can telecommute to work over great distances.

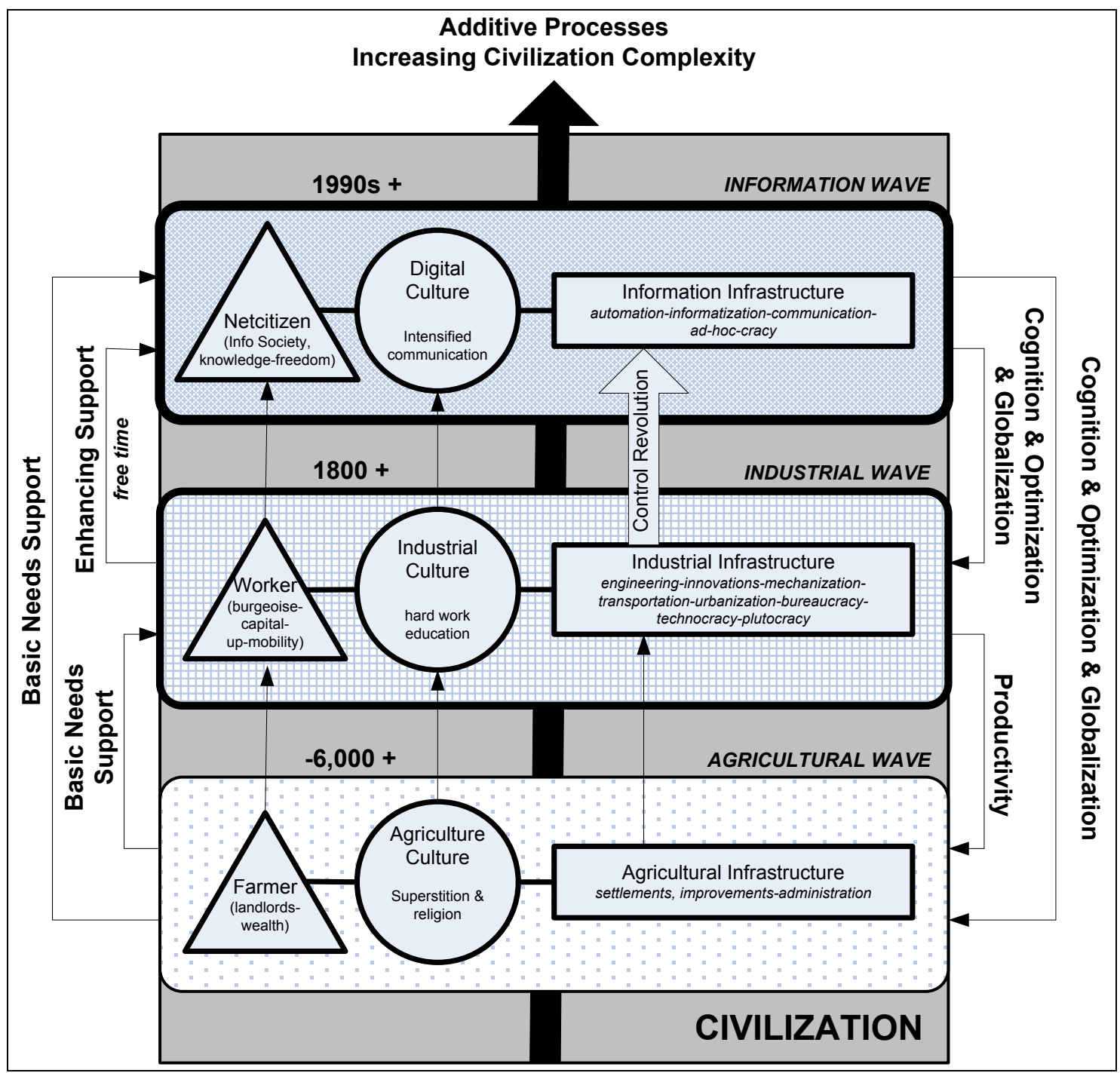

Figure 7. The Role of the Information Wave in Supporting other Civilization Waves

The Information Wave is not just a matter of technology and economics. It involves morality, culture and ideas as well as institutions and political structures. It implies, in short, a true transformation of human affairs (Toffler \& Toffler, 1994).

On the other hand, the unwise application of the Information Wave may be harmful for humans. Let's pose the following questions for civilization decision-makers:

- Is it wise to design automation, robotization, and informatization in such a way that their operators only watch the screens of many instruments but have little to say in the development control of a product? Sooner or later society will be divided into two groups of 
people: "thinking" designers and "thoughtless" users of such systems. It may lead to more productive solutions, but it may also degrade people and create a bifurcated society.

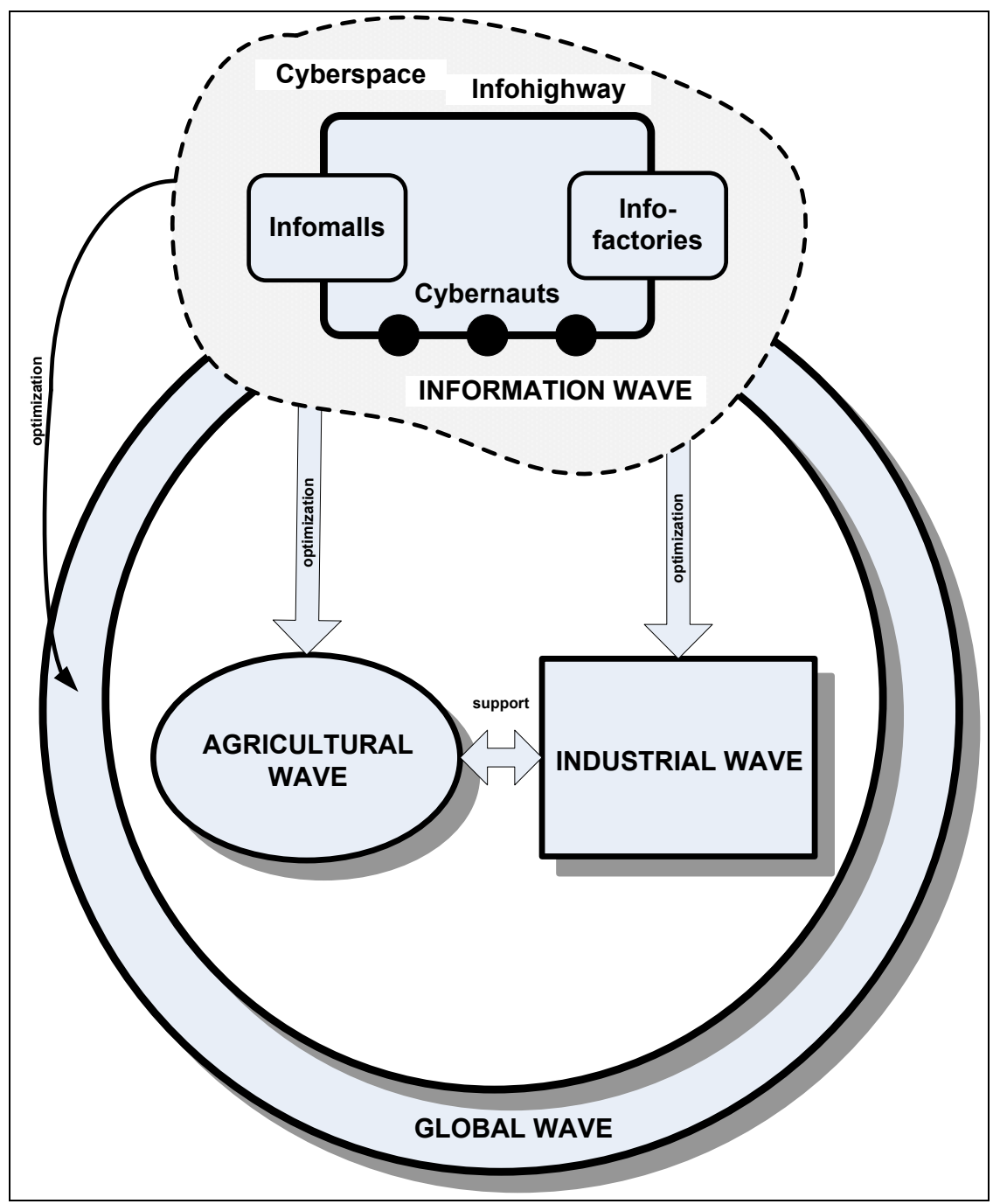

Figure 8. The Architecture of the Information Wave (Targowski 2009a) (Virtual and Communicating Things Waves Are Not Shown)

- Whether the world should unwisely apply automation, robotization, and informatization to reduce employment, when population growth and the demands of workers have interests often directly in contrast to strategies of efficiency?

- Whether the business and public administration should imprudently apply automation, robotization, and informatization to promote endless economic growth, while the reserves of strategic resources are depleting and sooner or later civilization as we know it will literally run out of gas?

There are plenty of such questions which face civilization now. Most of the time they are neglected, sometimes with catastrophic results. The potential of the Information Wave is in optimization of economic performance as well as to an even greater extent the wise control of civilization. 


\section{The Rise of the Virtual Wave at the Beginning of the $21^{\text {st }}$ Century}

When virtual mode was first introduced in information technology, it applied to memory simulated by the computer, that is, memory not actually built into the processor. Over time, though, the adjective has been applied to entities such as things, organizations, processes, and people that really exist and are simulated by means of information technology. For example, virtual conversations are conversations that take place over computer networks, and virtual communities are genuine social groups that assemble around the use of e-mail, webpages, and other networked resources. The adjectives virtual and digital and the prefixes e- and cyber- are all used in various ways to denote information, things, activities, and organizations that are realized or carried out chiefly in an electronic medium. Virtual tends to be used in reference to entities that mimic their "real" parallels. Thus a digital library would simply be a library that applies information technology, whether a brick-and-mortar library equipped with networked computers or a library that exists exclusively in electronic form, whereas a virtual library could only be the latter of these. The prefix e- is generally preferred when speaking of the commercial applications of the Web, as in ecommerce, e-cash, and e-business, whereas cyber- tends to be used when speaking of the computer or of networks from a broader cultural point of view, as in cybersex, cyber-church, and cyberspace. But like everything else in this field, such usages are evolving rapidly, and it would be rash to try to predict how these expressions will be used in the future ( see The American Heritage ${ }^{\circledR}$ Dictionary of the English Language, Fourth Edition).

Virtual worlds have exploded out of online game culture and now capture the attention of millions of ordinary people: students, husbands, wives, fathers, mothers, workers, and retirees. Devoting dozens of hours each week to massive multiplayer virtual reality environments - such as Civilization, World of Warcraft, or Second Life - these millions are the start of an exodus to the refuge of the virtual, where they experience life under a new social, political, and economic order built around fun (Castronova, 2007).

The development of the Global Economy in the 2010s is well established. The integrated information infrastructure has led to a boom in the development of social networks. In the past several years, some networks have thrived, some have vanished, and hundreds of new ones have appeared. It has become a huge area to follow, and nowadays one estimate is that about 500 large social networking sites offer services for about 1.242 billion users, as Table 1 illustrates the richness of this kind of info-communication-driven socialization.

These 1,635,000,000 users of global social networks today create the Global Virtual Society (GVS), which is mostly composed of young and middle aged people (a new emerging global information elite). They exchange info-communication (via informing systems) about facts, events, feelings, situations, activities, pictures, videos, and opinions faster and more frequently than they could in the real environment [1.06 billion users visited Facebook in December 2012 ("Number of active users at Facebook," 2013).

These facts are very encouraging, since the world in the 2010s is not in good shape. Some civilizations, such as Western, Eastern, and Islamic, are in conflicts and wars. The global economy economically flattens the world at the cost of Western Civilization, which economically declines, because it is outsourcing its industry to less developed civilizations, where the cost of labor is low. The world needs new ideas and political will to improve its well-being. To do so, the hope is in the young generation which populated and even created the GVS (complex of social networks).

In the spring 2010, just after being elected, Britain's Prime Minister David Cameron wanted a few tips from somebody who could tell him how it felt to be responsible for, and accountable to, many millions of people who expected things from him, even though in most cases he would 
never shake their hands. Prime-Minister Cameron turned not to a fellow of government but to Mark Zuckerberg, the founder and head of Facebook, the largest social network. These two men talked about ways for networks to help governments, for example how to generate ideas on cutting public spending. They talked as masters of two great nations (Carlson, 2010).

Table 1. The Ranking of the Largest Nations by its Citizenships/Memberships in 2012

\begin{tabular}{|llll|}
\hline RANKING & NATION & POPULATION & GLOBAL VIRTUAL \\
SOCIETY
\end{tabular}

Facebook is the fastest growing social network in the 2010s, and within a few years should reach 1.5 billion users. It will be a social network with the potential to become the first example of the Global Virtual Nation (GVN) in civilization. To become such a nation, Facebook must transform itself into a service not for profit and form a government, agencies, and acquire citizens. This transformation should take some time in the near future, and it will require some strong societal and organizational will as well as initial capital.

The emerging social networks lead to the birth of collective "mindspheres" of intelligence, knowledge, and wisdom at global and national levels. Figure 9 illustrates the architecture of these new collective mindspheres. Along with practice, these mindspheres can multiply at all levels of the nation, for example at the level of the village, town, township, county, city, and state. It will take time before such mindspheres can become organized. This certainly will not take place everywhere, but it will where there is social will and organizational might. 


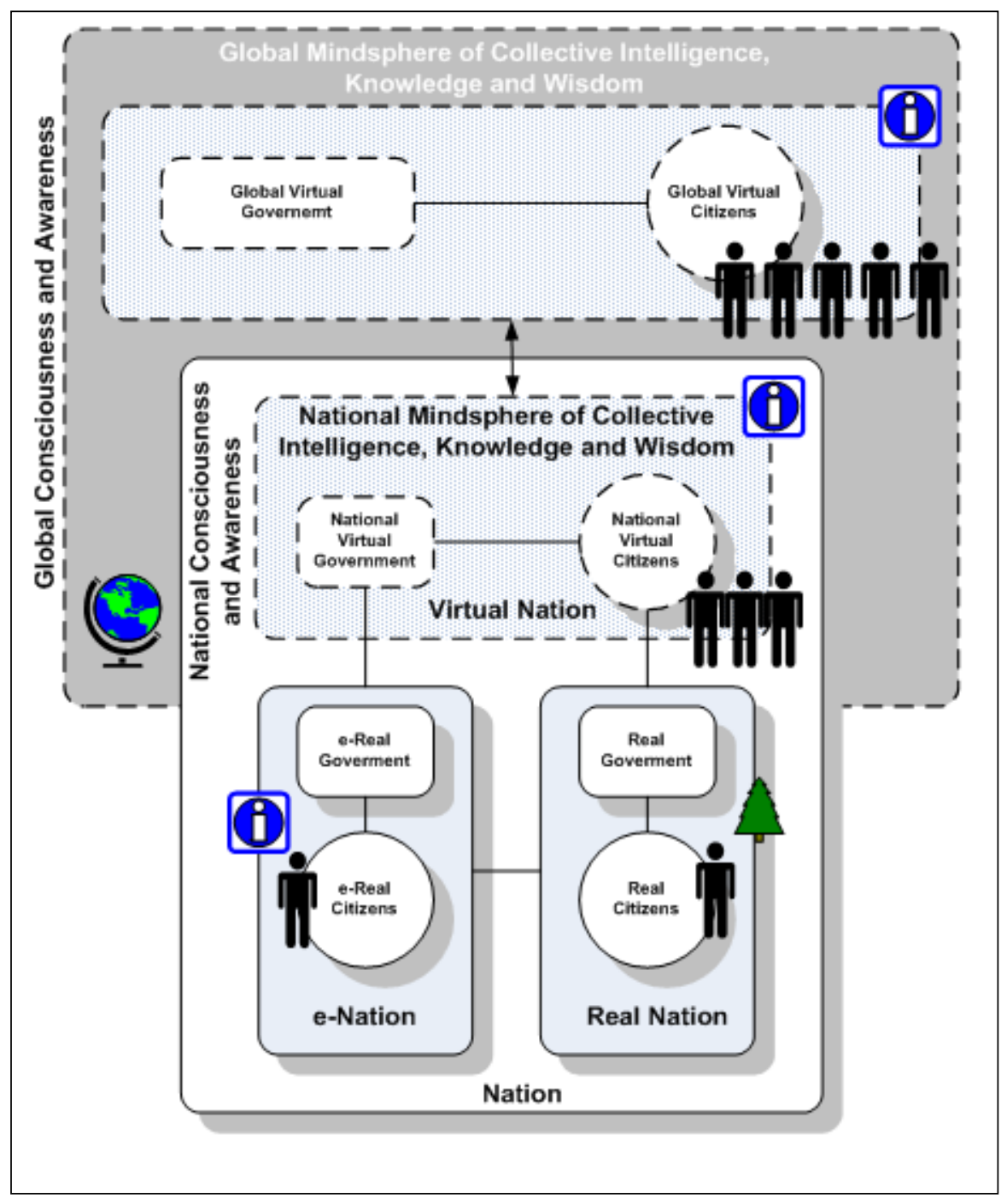

Figure 9. The Architecture of Emerging Collective Mindspheres at the Global and National Levels in the $21^{\text {st }}$ Century (Targowski, 2015)

These mindspheres working in universal cyberspace should facilitate the collection and exchanges of ideas and solutions which may liberate us from social and political hierarchies that stay in the way of mankind's advancement (Lévy, 1997). Pierre Lévy says that perhaps "it is a utopia but is an achievable utopia." Furthermore, he thinks that "we cannot only exchange information but think together, share our memories and our plans to produce a cooperative brain." This collective brain, or rather mind, can multiply our social and cognitive potential. With such a powerful tool, mankind's consciousness can become broader, deeper, and more sophisticated, and perhaps be able to solve what are currently unsolvable problems. Will we be ready with such a collective mind to stop the depletion of strategic resources of our civilization, which will deplete completely within 50-200 years if we do not find good solutions?

Of course this "rosy" picture is full of unexpected motives and actions triggered by computer hackers, criminals, and anti-social agents. Since the new virtual world has the same or even more intensified crimes as the physical world, it is, therefore, not yet a paradise or utopia!

Rather it is a hope for a wiser and better civilization which would like to last as long as possible. 


\section{The Rise of Virtual Civilization at the Beginning of the $21^{\text {st }}$ Century}

How good and how much money must one possess to be elected president of the Global Virtual Nation? What would be the nature of the virtual election? Can it be made more available for more candidates? Can it be free from the pressure of groups? Can it be free of fraud? Today it is too soon to answer these questions. The coming operational practice of the GVN certainly will elaborate procedures of the political processes and systems. It will be fascinating since it will also be the birth of a new civilization, which can be called Virtual Civilization. It will be the next layer upon the existing civilizations. For example, in the 2010s Western Civilization is being transformed into Global Civilization and also is transforming into Virtual Civilization. An American or Portuguese citizen functions in these three civilizations concurrently! It is a big challenge to be successful in such an environment.

It will also be interesting to see whether the Global Virtual Nation, created by Western Civilization, will be pro-Western, against it, or universal, which would be the most desirable position. Perhaps Virtual Civilization will be conducive for the development of Orwellianism; then again, it might just as well be against the Big Brother polity. Today it is too soon to state which way the new civilization will evolve.

In contrast to participative-representative democracy, practiced in Western Civilization today, the GVN will apply populist-direct democracy where to pass a bill, every citizen may vote electronically. Supposedly, every virtual citizen will belong to the information elite, which is well informed and aware of what is good or bad in a proposal being voted upon. The GVN will be dangerous for nations with authoritarian, dictatorial, and theocratic governments which neglect the public opinion. Today, China, Pakistan, Saudi Arabia, and other counties block Facebook operations and censor the Internet. In 1970s, totalitarian Poland did not tolerate the INFOSTRADA project, which allowed bypassing governmental communication channels in delivering public information (Targowski, 2009a, p.193).

The impact of the GVN upon real global organizations (e.g., the U.N., IMF, TWO, and other stateless corporations) and national governments can be big and decisive. If virtual citizens of the GVN agree on an issue and strategy, they may enforce directions in the real world, since those virtual citizens are also real citizens in particular countries where real governments rule. Today, most people feel that they have little to say about what the government does; an overwhelming majority say that the government is run by a few big, selfish interests. Therefore, the GVN provides the opportunity to organize those unsatisfied people and pursue their (not the particular interests) issues and solutions.

There is a question whether the GVN will take over civilization and govern real national governments. A somewhat similar case took place when the underpowered society in totalitarian Poland beat the dictatorship in 1989. This happened when the underground press exceeded the volume and truthful content of the official press. It was the victory of a well informed and motivated solidarity movement which overcame a powerful, militarized government. Later the whole Soviet Empire collapsed, mostly due to info-communication oriented policy of glasnost and pierostroyka implemented by M. Gorbachev.

The generalized model of the dynamics of Virtual Civilization is provided in Figure 10. 


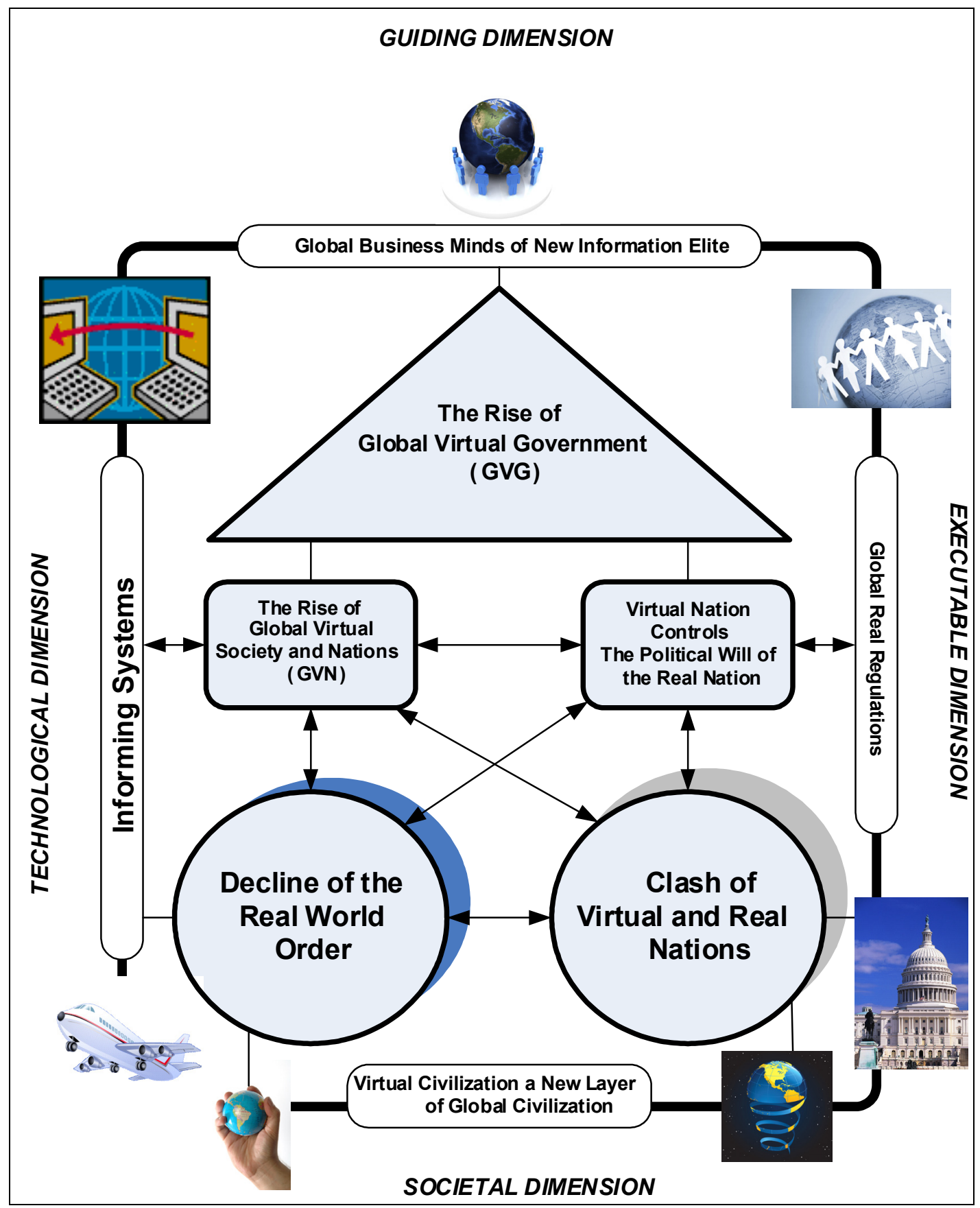

Figure 10. The Dynamics of the Virtual Civilization in the $21^{\text {st }}$ Century

One can expect that the GVN will create subunits under the form of virtual nations (VN). A virtual nation will organize a National Virtual Government (NVG) and National Virtual Citizens (NVC) around the important issues and solutions within the boundaries of a real nation. Lawrence Grossman (1995) already perceived the emergence of the electronic republic, where electronic voting and opinion-registering technologies will go from the bottom to the top (lawmakers). But as the practice shows, the lawmakers listen to the lobbyists rather than to their constituencies. It is true that the citizens' views are known in media and the political circles, but the citizens are rather passive and unable to implement their solutions through the official political parties, which are concerned with maintaining their own "jobs." It is a fact that the real citizens are unorganized 
and dispersed. An example of a certain kind of self-organization of unsatisfied citizens in America is the Tea Party in the 2010s.

Why is the Virtual Wave considered to have become Virtual Civilization in the $21^{\text {st }}$ century? Most outstanding, the latter satisfies all the criteria of a civilization as it is defined in Table 2 and has created its own independent, virtual society, parallel to the real one.

Table 2. The Classifying Criteria of the Virtual Civilization

\begin{tabular}{|c|c|}
\hline CRITERIA & ATTRIBUTES \\
\hline Space boundaries & $\begin{array}{l}\text { World-wide unlimited, socially constructed work and leisure space in } \\
\text { cyberspace. It is an extraterritorial space with a post-national culture and } \\
\text { in some circumstances even post-nations. }\end{array}$ \\
\hline Time span & $\begin{array}{l}\text { Centuries/millennia - as long as info-communication technology as in- } \\
\text { forming systems is operational. }\end{array}$ \\
\hline Religion (ideology) & $\begin{array}{l}\text { Unlimited freedom, cyberspace, and progress supported by collective } \\
\text { intelligence - to secure common good in an alternative virtual world, } \\
\text { since the "real" one is going in the wrong direction in the } 21^{\text {st }} \text { century. }\end{array}$ \\
\hline Society & $\begin{array}{l}\text { Virtual global, local and between communities, including the Virtual } \\
\text { Global Society and Virtual Global Nation (possibly) living in spacial } \\
\text { dispersion of social, political, and material processes. }\end{array}$ \\
\hline Culture & $\begin{array}{l}\text { Virtual techno-culture (Robins \& Webster, 1999) is the culture that has } \\
\text { emerged, or is emerging, from the use of computer networks for com- } \\
\text { munication, entertainment and business (Horn, 1998). E-values: con- } \\
\text { nected, expected feedback, rhythm, productivity, velocity, impatience, } \\
\text { techno-centrism, cyber-ethics, informed, optimization, big-picture vs } \\
\text { small-picture, global awareness, self-conciseness. E-behavior: net- } \\
\text { centric, anytime, anywhere, "death" of distance, no-middleman, curiosi- } \\
\text { ty, discovery, digital \& virtual divide, information wealth, poverty of } \\
\text { attention (Targowski, 2009a, p. 306). It is also the study of various social } \\
\text { phenomena associated with the Internet and other new forms of network } \\
\text { communication, such as online communities, online multi-player gam- } \\
\text { ing, and text messaging (Jones, 1997). In the 1990's information took a } \\
\text { sharp turn away from the concrete and tangible to the abstract and intan- } \\
\text { gible (Rheingold, 1993). }\end{array}$ \\
\hline Infrastructure & $\begin{array}{l}\text { Computer networks and storage (online cyberspace as a repository for } \\
\text { collective cultural memory, whose narrative is created by its virtual soci- } \\
\text { ety) used through informing systems. }\end{array}$ \\
\hline
\end{tabular}

Virtual Civilization (of the infrastructural character) is to a certain degree a parallel entity to real Global Civilization in space and time. However, the former's goal is to control the latter for securing the common good. Virtual Civilization's main infrastructure is collective intelligence (Lévy, 1997), which develops and shares a strong ability for solving problems among virtual members and is based on a word-wide retrieval of knowledge and wisdom kept in digital format.

Virtual Civilization penetrates horizontally all other autonomous civilizations as well as the Global Civilization, as it is depicted in Figure 11. 


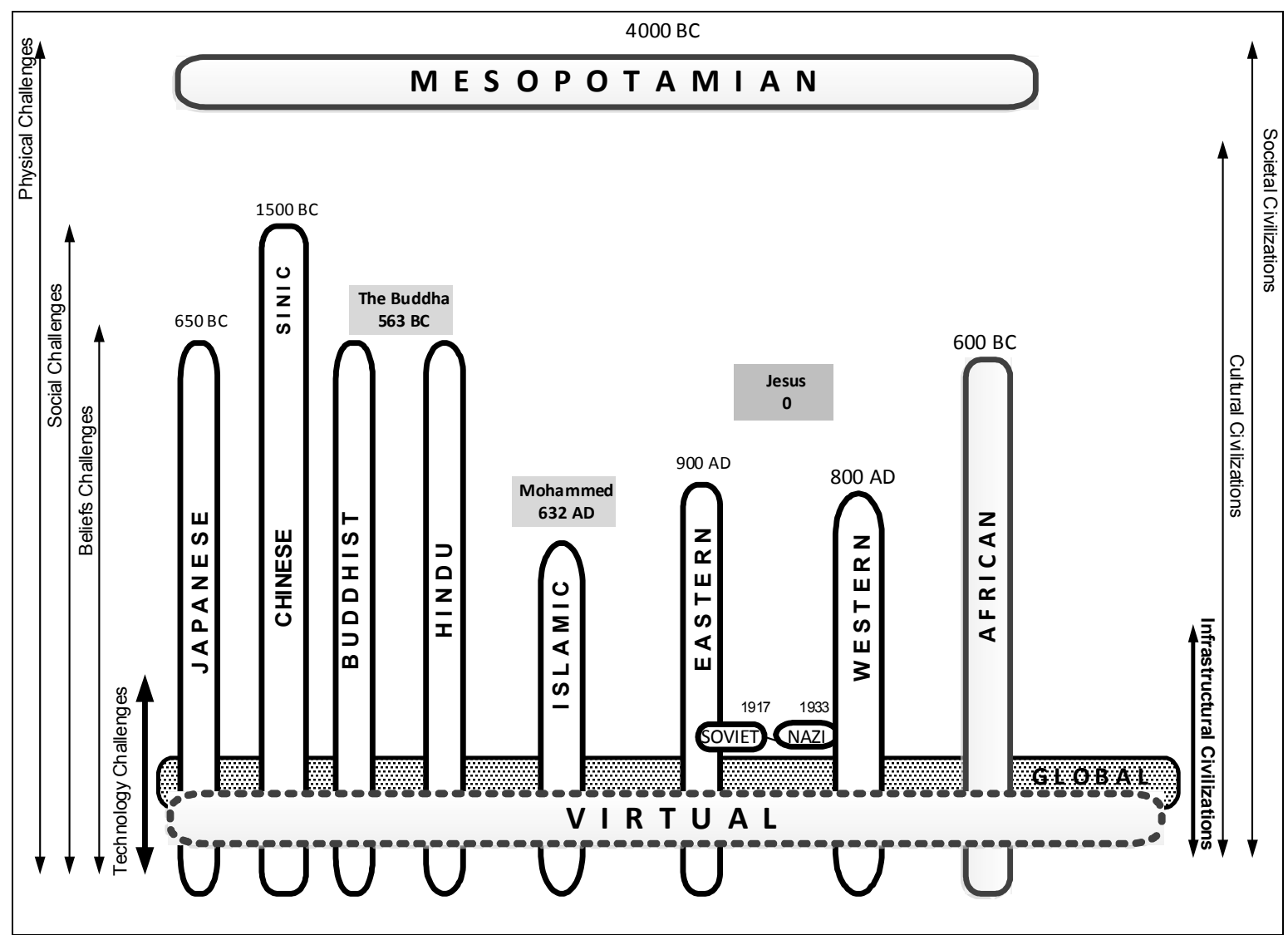

Figure 11. Virtual Civilization among other Civilizations in the $21^{\text {st }}$ Century

\section{The Future of Informing Systems and Their Ethics Question}

The future of informing systems, regardless of their societal values is almost unlimited since their advancements supposedly represent the universal scientific progress. It could be right if working people (labor) replaced by these systems could have another sources of income. Certainly they do not have it, and the question is what is more important; the advancement of informing systems to its limit, which is the sky, or well-being of working people? It is the strong ethics issue which must be addressed by governments, legislative bodies, professional associations, schools, and colleges.

The first issue of informing systems-driven business ethics is the well-being of society, which is under pressure from connected automation, robotization, and faceless service systems since they lead toward a labor-less economy and structural unemployment. This issue will be addressed through the following definitions of appropriate laws. Of course these laws are just a few examples of this kind of problems and are not limited to them in the context of a New Economy and Society's sustainable functionality in the early $21^{\text {st }}$ century.

\section{Robotics Laws}

The Three Laws of Robotics, also known as Asimov's Laws, are a set of rules devised by the science fiction author Isaac Asimov. The rules were introduced in his 1942 short story "Runaround", although they had been foreshadowed in a few earlier stories. The Three Laws are: 
1. A robot may not injure a human being or, through inaction, allow a human being to come to harm.

2. A robot must obey the orders given to it by human beings, except where such orders would conflict with the First Law.

3. A robot must protect its own existence as long as such protection does not conflict with the First or Second Law (Asimov, 1950).

The development of AI in advanced informing systems is a good business, and businesses are extremely unconcerned about necessary precautions, particularly ethical ones. Some examples include the tobacco industry and the nuclear industry. Not one of these businesses has said from the beginning that important protections are necessary, and every one of them has attacked externally forced precautions, while none has recognized a complete proclamation against ever affecting harm to humans (Sawyer, 1991). Furthermore, Ray Kurzweil (2005) predicts the technological singularity will occur around 2045 when computers will think faster than humans. The question is why would humans risk building such computers which could harm or kill them? He says that the development of such computers is scientific progress and as such cannot be controlled by any policy. What about the cloning of humans? Is it medical progress, even though the widely accepted policy states that human cloning is illegal and may harm clones.

\section{Automation Laws}

According to known facts, factory automation caused, in a uniform manner, a worldwide decline in manufacturing jobs during the 2000s - 2010s not only in developed countries but in developing countries as well. Hence, the laws of Automation Systems - driven by informing systems should be implemented into society's undertakings since these systems are very sensitive in terms of the well-being of society.

The automation systems are one of the most complex systems in civilization which triggered tremendous developmental trends in science and technology in the 20th century. They looked very promising at their early stages but later provided many doubts about their positive role in society. The automation systems designed for better effectiveness and reliability \& quality are positive as long as they do not harm and endanger human beings and society.

With respect to these issues, Andrew Targowski and Vladimir Modrák (2011) offered the following Laws of Automation in Manufacturing:

- Law I. Do not implement high automation technology if you are not sure that the same goal can be achieved by another means.

- Law II. Do not implement automation technology with the aim to totally eliminate human presence in the manufacturing process.

- Law III. Do not develop automation which harms society or endanger human race.

\section{Service Systems Laws}

The service economy which dominates the Western civilization in the early $21^{\text {st }}$ century is steadily moving towards an elektronization of services which eventually will replace face-to-face communication by faceless expert systems, causing among many things the death of customer service. In order to protect quality services the following laws of service systems should be applied (formulated by Targowski, 2009a, p. 273):

- Law I - Do not develop service systems without a human presence.

- Law II - Do not develop service systems which harm society. 
- Law III - Do not develop service systems which endanger the human race.

The Law I protects people against passivity. Law II protects society against structured unemployment. Law III protects the human race against the bifurcation into two kinds of species, one kind which is highly developed since it is engaged in the development of sophisticated service systems, and a second kind which is composed of passive users whose skills are limited to knowing when to click the entry button.

In order to integrate all these laws into one coherent discipline, a new one should be pursued. Perhaps it should be named Informingsophy (Technosophy), which should investigate wise infocommunication engineering for wise civilization. This kind of engineering should be developed today and aimed at the sustainability of our civilization in times of shrinking strategic resources. It is widely known that a large population becomes too large to sustain our Western lifestyle, even in the short-term future. Hence, the future is now, and Informingsophy (Technosophy) is needed today as never before.

Once we learned that the applications of the Internet of People's almost unlimited potential need some wisdom in order to not harm society (for example through addiction and isolation), we today are facing the next challenge of the rising Internet of Things with an even bigger potential for improving and/or harming society if it is applied on a technological impulse only. Certainly, this new info-communication channel provides progress for machine-to-machine communication but not solutions for any societal problems. Such positive technology used to be the case when technology or machines in general supported culture (Mumford, 1934), but nowadays there is a rising understanding that machines conquer culture. If it is true, it is bad for the well-being of the society.

\section{Conclusion}

1. Virtual Civilization has transformed from the Virtual Wave into Virtual Civilization due to advancements in info-communication technology as informing systems in the $21^{\text {st }}$ century, exemplified by the ability of the Internet to secure operations of virtual organizations and social networks. Therefore, one can characterize Virtual Civilization as having infrastructural character.

2. The mission of Virtual Civilization is to control public policy of other real civilizations to secure the common good in the real societies. At least such a mission is exemplified in the practice of some virtual communities at the dawn of the $21^{\text {st }}$ century.

3. Today it is too soon to judge the impact of Virtual Civilization upon the real ones. However, despite the positive aspects, like the quest for the common good, one can notice negative ones as well in the young generation, exemplified by a shortened span of attention and the desire for constant (electronic in fact) fun, playing computer games for long hours and engaging in "empty talk" in virtual mediums. For example students 18-24 years old learn less, since on average they send and answer about 100 text messages every day (Smith, 2011). This is about 5 times more than a faculty is reading and answering e-messages every day. Some eager students send twice as many messages per day (200).

4. The quest for the common good by virtual society may limit or even replace representative democracy by direct democracy which although it eventually may create a few positive policies, it may also trigger permanent political chaos in real civilizations.

5. The many e-communications among people from different parts of the world are diminishing local interrelations and intensifying connectivity among international or/and distant, parochial cultures, which eventually will separate, isolate and alienate individuals in their real living places. 
6. At this time it is very improbable that virtual society can be regulated by real society. This means that Virtual Civilization, on one hand, can be positive, but on the other hand it can be harmful for humanity which is living in a declining civilization due to overpopulation, superconsumerism, depletion of strategic resources and environment degradation.

\section{References}

Asimov, I. (1950). i, ROBOT. New York: Bantam Dell.

Bell, D. (1973). The coming of post-industrial society: A venture in social forecasting. New York: Basic Books.

Carlson, N. (2010, June 21). Mark Zuckerberg goes to England, meets the prime minister. Business Insider. Accessed 6-5-2015 http://www.businessinsider.com/mark-zuckerberg-goes-to-england-meets-theprime-minister-2010-6\#ixzz3cCZbNEXd

Castronova, E. (2007). Exodus to the virtual world. New York: Palgrave MacMillan.

Cairncross, F. (1997). The death of distance. Boston: Harvard Business School Press.

Cohen, E. (1999). From ugly duckling to swan: Re-conceptualizing information systems as a field of the discipline informing science. Journal of Computing and Information Technology, 7(3), 213-219.

Denning, P. J., Comer, D. E., Gries, D., Mulder, M. C., Tucker, A., Turner, J., \& Young, P. R. (1989). Computing as discipline (Final report of the task force on the core of computer science). Communications of the ACM, 32(1), 9-23.

Gackowski, J. Z. (2011). Informing for operations. Santa Rosa, CA: Informing Science Press.

Grossman, L. (1995). Electronic republic. New York: Viking.

Hardy, Q. (2012, July 9). Information technology spending to hit \$3.6 trillion in 2012, report says. New York Times.

Horn, S. (1998). Cyberville: clicks, culture, and the creation of an online town. New York: Warner Books.

Huntington, S. (1996). The clash of civilizations and remaking of world order. New York: Simon \& Schuster.

Jones, S. (Ed.). (1997). Virtual culture: Identity \& communication in cybersociety. London: Sage Publications.

Kurzweil, R. (2005). The singularity is near. New York: Viking.

Lévy, P. (1997). Collective intelligence, mankind's emerging world in cyberspace. New York \& London: Plenum Trade.

Mumford, L. (1934). Technics and civilization. New York: Harcourt Brace \& Co.

McLuhan, M. (1962). The Gutenberg galaxy. Toronto: University of Toronto Press.

Melko, M. (1969). The nature of civilization. Boston: Porter Sargent Publisher.

Number of active users at Facebook over the years. (2013, May 1). Associated Press. Accessed 6-5-2015 http://news.yahoo.com/number-active-users-facebook-over-230449748.html

Rheingold, H. (1993). A slice of life in my virtual community. In L. M. Harasim (Ed.), Global networks: Computers and international communication (pp. 57-80). Cambridge, MA: MIT Press.

Robin, K., \& Webster, F. (1999). Times of the technoculture. London and New York: Routledge.

Sawyer, R. J. (1991). On Asimov's three laws of robotics. RANDOM MUSINGS. Accessed 6-5-2015

http://www.sfwriter.com/rmasilaw.htm

Simpson, G. (1991). Montreux MetaResort brochure. Reno, NV: Wellness Development Ltd. 
Informing Systems and Information Waves

Smith, A. (2011). Americans and text messaging. PewResearch Center. Accessed 3-4-2015 http://pewinternet.org/Reports/2011/Cell-Phone-Texting-2011.aspx

Targowski, A. (2009a). Information technology and societal development. Hershey \& New York: IGI Global.

Targowski, A. (2009b). Towards a composite definition and classification of civilization. Comparative Civilizations Review, 60, Spring.

Targowski, A. (2015). The virtual civilization in the $21^{\text {st }}$ century. New York: NOVA Science Publishers.

Targowski, A., \& Modrák, V. (2011). Automation with a human face. Dialogue and Universalism, XXI(2), 5-20.

Toffler, A. (1980). The third wave. New York: Bantam Books

Toffler, A. \& Toffler, H. (1994). Creating a new civilization. Atlanta, GA: Turner Publishing.

Toynbee, A. (1995). A study of history. New York: Barnes \& Noble.

Wheeler, J. A. (1990). A journey into gravity and spacetime (Scientific American Library.) New York: W.H. Freeman.

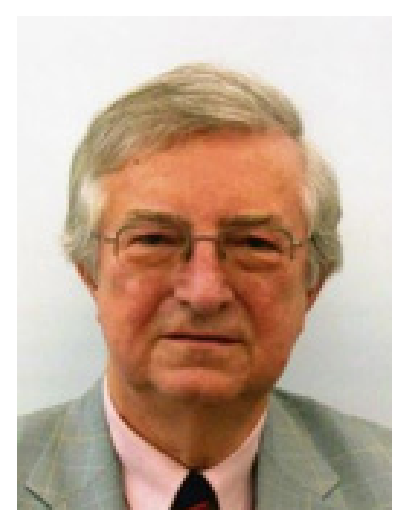

Andrew Targowski is a Polish-American informatician, civilizationist and philosopher. He is an author of 37 books on information technology, civilization, philosophy, and political science, a professor of computer information systems at Western Michigan University (USA), President Emeritus of the International Society for the Comparative Study of Civilizations (2007-2013). In Poland in the 1970s he initiated the INFOSTRADA Project which has been adapted as the Information Superhighway in the U.S. and provided a new paradigm for a New Economy, triggered by the Internet. He initiated and was the Chief Developer of the PESEL system, providing a social security number for 38 million Polish citizens. 